This correlation was not seen when the patients were given non-tailored messages about smoking during scanning. Nature Neurosci. doi:10.1038/ nn/2761 (2011)

\section{BIOLOGY}

\section{Predators trigger plankton stealth}

Tiny water-dwelling organisms called phytoplankton can adopt a 'stealth' mode to avoid the attentions of predators.

Many types of plankton group together into chains, and some respond to grazers by increasing their group size until the chains are too large to eat. Erik Selander of the Technical University of Denmark in Charlottenlund and his colleagues show that predators can trigger the opposite response in Alexandrium tamarense.

When exposed to small plankton-eating crustaceans called copepods, chains of Alexandrium adopt stealth behaviour, splitting into single cells or very short chains and swimming more slowly. The phytoplankton drastically reduces its encounters with grazers through this mechanism, the authors report.

Proc. Natl Acad. Sci. USA doi:10.1073/pnas.1011870108 (2011)

\section{EPIDEMIOLOGY}

\section{Farm kids benefit from microbes}

Exposure to diverse microbes could explain why children who grow up on farms are less likely to develop asthma than their suburban counterparts.

Previous work showed that children raised on farms are protected from childhood asthma and a class of allergic reactions called 'atopy'. Now, Markus Ege of the University Children's Hospital Munich in Germany and his colleagues have analysed the microbial populations in dust collected from 933 children's rooms. They found that bacteria and fungi were more numerous and widespread in samples collected for children who live on farms. They also found that the risk of asthma and atopy decreased as the number of microbial taxa increased. In particular, fungi from two genera, Eurotium and Penicillium, were tightly associated with reduced asthma risk.

N. Engl. J. Med. 364, 701-709 (2011)

\section{CLIMATE CHANGE}

\section{Sea-ice models don't measure up}

Climate models do a poor job when it comes to simulating sea-ice change in the Arctic.

Michael Winton of the

Geophysical Fluid Dynamics Laboratory in Princeton, New Jersey, compared data from the era of satellite observations and five state-of-the-art climate models of Northern Hemisphere sea-ice cover. All of the model simulations considerably underestimated the observed sea-ice decline.

Substantial natural variability in the annual sea ice would be necessary to explain the discrepancy between observations and even the best-performing model. It is more likely that current climate models are not nearly sensitive enough to accurately gauge the behaviour of sea ice in response to warming, the authors say.

J. Clim. doi:10.1175/

2011JCLI4146.1 (2011)

\section{GENETICS \\ Clues from big-hearted mice}

Mice bearing the mutations underlying two human heart syndromes have pointed the way to possible treatments. Noonan and LEOPARD syndromes both cause short stature, facial deformities and abnormally thick hearts that cannot pump properly.

Benjamin Neel and

Toshiyuki Araki of the Ontario

Cancer Institute in Toronto,

COMMUNITY CHOICE

The most viewed papers in science

\title{
Dogs keep an eye on their owners
}

\section{Highly Read \\ on elsevier.com up to 2I February}

Dogs are famously good at reading human body language, following human gaze and stealing human food. But not all humans are equal in the eyes of Canis familiaris.

Paolo Mongillo and his colleagues at the University of Padua in Italy investigated the attention dogs paid to their owners and to strangers. Each dog watched as its owner and a stranger walked back and forth across a test room in opposite directions, popping in and out of two doors.

Not surprisingly, the dogs kept their eyes on their owners most of the time, and stared at the doors they had gone through. At least, young dogs did. Dogs over the age of seven didn't stare at the door their owners had gone through with the same frequency, perhaps indicating some cognitive decline, or that they have learned over the years that their owners always come back in the end.

Anim. Behav. 80, 1057-1063 (2010)

Canada, and their co-workers, engineered mice to have the mutation in the Raf1 gene that underlies Noonan disease. In addition to features of the human syndrome, the mice had increased activity of the Mek protein. Pups given a Mek inhibitor started small but they grew faster and caught up with normal mice by a couple of weeks after birth.

Meanwhile, Neel and Maria Kontaridis of Harvard Medical School in Boston and their colleagues inserted into mice the mutation in the Ptpn11 gene that causes LEOPARD syndrome. The activity of a protein called mTor was abnormally high in these mice, and giving them the mTor inhibitor rapamycin repaired heart defects.

J. Clin. Invest. doi:10.1172/

JCI44929 (2011)

J. Clin. Invest. doi:10.1172/

JCl44972 (2011)

\section{Slip and slide pores for sensors}

Taking their inspiration from nature, researchers have coated nanopores with fluid bilayers to sense single proteins. The

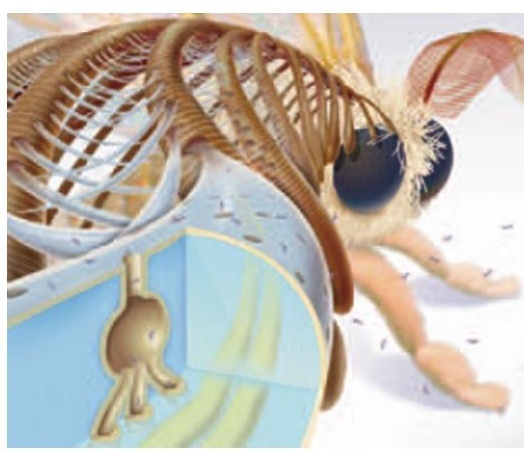

creation, which mimics the pores in the olfactory system of a silk moth (pictured), was developed by Michael Mayer at the University of Michigan in Ann Arbor, Jerry Yang at the University of California, San Diego, and their team.

By modifying the lipid with specific ligands, the researchers can control which proteins move through the pore, and how long their journey takes. The system can also be tweaked to slow down proteins that would otherwise translocate too fast to be analysed accurately.

Nature Nanotechnol. doi:10.1038/ NNANO.2011.12 (2011)

\section{NATURE.COM}

For the latest research published by Naturevisit:

www.nature.com/latestresearch 